\title{
National Models for Regulating On-board Protection of Vessels: Some Cross-cutting Issues
}

\author{
Birgit Feldtmann, Christian Frier \& Paul Mevis*
}

\section{Introduction}

The topic of this special issue is flag states' legal approaches to on-board protection of merchant vessels by Privately Contracted Armed Security Personnel (PCASPs) or Vessel Protection Detachment (VPDs), a development which was especially triggered by Somalibased piracy. The idea of armed on-board protection is basically to merge targets (ships and seafarers) and their defenders (guards) into a single defensive unit and thereby minimise the risk of successful hijackings. This approach, which has to be considered on the national level in accordance with the flag state principle, is part of the wider approach that the international community has taken, and which has contributed to a huge reduction in attacks and hijackings for the benefit of crews, ships and cargoes.

On-board protection is a phenomenon that provokes a number of legal challenges and uncertainties, which from a regulatory perspective have to be addressed on the national level and in the wider context of the international law of the sea. The four country reports in this special issue illustrate the diverse approaches and the underlying policy concerns which can come into play when flag states develop their own approach and regulatory model. The in-depth analyses in the country reports provide a picture of the issues at stake from a national perspective.

In the light of the informative and comprehensive country reports, one could be tempted to engage in a classic comparison of the contributions. However, that is not the approach we have chosen. Instead, we will leave any comparison of the national regulatory models to the reader. Our approach is to focus on a number of crosscutting issues that illustrate the legal considerations and dilemmas at hand and provide opportunities to reflect and discuss overall questions associated with the use of on-board protection. Those cross-cutting issues are

Birgit Feldtmann is professor (mso) at the Department of Law, Aalborg University. Christian Frier is research assistant at the Department of Law, University of Southern Denmark. He obtained his PhD in Law in March 2019. Paul Mevis is professor of criminal law and criminal procedure at Erasmus University Rotterdam. interrelated and overlapping; it is our belief that they lead us to questions of universal interest. Of course, we take into account the fact that the country reports encompassed in this special issue represent a small but at the same time diverse sample from the total number of flag states that allow armed guards.

\section{Cross-cutting the Legal Framework}

Having to find their own way, it is not surprising that Denmark, Germany, Italy and the Netherlands started to debate and draft their specific legal approach within the sphere of their own legal system and on the basis of their respective legal system's underlying ideas and approaches. In all four countries, the development of the regulatory models was, more or less, connected with fundamental discussions about the interests at stake and national opinions on the rule of law. From a starting point, we can see the difference between countries with no regulation that allow PCASPs (Italy, the Netherlands and Denmark) and Germany where the discussion started because the actual general legislation seemed to allow 'too much' and therefore it was felt there was a need to regulate the use of PCASPs far more restrictively in a lex specials. We also see, more importantly, the significant difference between the two countries (Italy and the Netherlands) which were convinced that a statebased approach (VPDs only) is preferable or at least were convinced this was the correct starting point of national regulation. The somewhat 'idealistic' statebased approach rather than 'privatisation approach' by the Netherlands and Italy was in due course modified, triggered by the fear of losing ground: the increase in the number of flag states allowing PCASPs and the subsequent threat of reflagging and reduction of the national fleet seemed to be the elephant in the room pushing for a level-playing field.

One interesting observation in the context of the different national legal frameworks is the diverse role of the 'state monopoly on violence' argument: in the Netherlands, it still is considered to be the underlying ruling principle for the new 'VPD, unless' approach, while the German position seems to be that the use of private armed guards does not contradict the state's monopoly 
on the use of force, as PCASPs do not exercise any public powers. This illustrates that common principles of (public) law can have relatively different weights and interpretations in domestic legal discussions, when compared with similar discussions in other countries. We address the question of the use of force in further detail as follows.

The above-mentioned observations might make us ask which of the two different approaches is better. Two remarks are relevant in this regard: first, the fight against piracy is not only about protecting a certain vessel on its journey and thereby protecting the economic interest of a given ship owner. Basically, piracy is a form of violent international organised crime and a threat to human lives, the freedom of navigation and free trade as a common interest. It is, at least as far as Somalia is concerned, the result of the political, social and economic chaos in that country. If a state chooses to perceive the fight against piracy in the broader perspective of law enforcement, justice, regional capacity building and upholding law and order at sea, the choice for a VPD approach might be obvious. However, as illustrated in the international perspective in this special issue, the placement of state representatives on private vessels is not without legal challenges. It can also be argued that a PCASP approach does not necessarily mean that a state is neglecting the wider perspective. Both the German and the Danish answer appears to be that the approach can be two-fold - with a 'privatisation solution' on board commercial vessels and a state-based approach by participating in international counter-piracy operations at sea and in capacity building on shore at the same time. On that note, it can be concluded that the general tendency seems to be that at the current stage of developments today, states seem to be downsizing the law enforcement approach (e.g. by deploying fewer naval vessels to counter piracy) and with the focus now on the protection of economic interests.

The second observation concerns what could be described as the density or comprehensiveness of the legal framework: if we compare the two countries with a PCASP approach from the very beginning (Denmark and Germany), it is obvious that within this common approach there exist substantial differences in the approaches towards the governance and control of PCASPs (we will get back to this in due course). However, the essential observation is this that while Denmark to a large extent leaves further regulation to the private sector, Germany has chosen a (public) law approach with rather strict and detailed regulation. In other words, the question is not necessarily whether the option of public or private armed protection is preferable as such. The real factor seems to be the question of how and to what extent the issues at stake are regulated and enforced in practice. This means that the quality of a given approach depends on the broader goals and aims of the respective regulation in a certain country and the way this works out in reality.

\section{Controlling Security Providers: The Cross-cutting Issue of Authorisation}

A prerequisite for using armed on-board protection in the first place is the requirement that authorisation must be obtained. This functions as a guarantee for ensuring that only reputable security providers are contracted. A common feature in the four regulation models is that authorisations are issued by public authorities. Notwithstanding, three interesting points can be deduced from the country reports. First, the recipient of the authorisation and the level of detail which must be observed differs to a large extent. Generally, it is a requirement for supplying armed on-board protection that the security provider has obtained national authorisation beforehand. This is the situation under both German and Italian law and stipulated in the Dutch draft proposal. Also, the German authorisation scheme borrows very heavily from international standards as noted by Salomon. The density of the authorisation scheme cannot be accounted for in the Dutch proposal but coming from a VPD solution only, it is fair to assume that such an authorisation scheme will not be lax. Interestingly, as noted by Frier, the Danish authorisation scheme varies greatly from the other systems in the way that the addressee of the authorisation is in fact only the ship owner. Thus, security providers are not subject to individual administrative control or authorisation under Danish law.

Second, under some of the regulation models the authorisation must not be mixed up with the need for a separate licence to hire security providers for a certain transport (the Netherlands) or the allowance to use certain weapons such as automatic firearms (Italy). This leads to another crucial issue in connection with armed on-board protection, which does not seem to be fully addressed in all flag states: the issue of how to get weapons on board and the legal challenges connected to having weapons on board while passing through other coastal states' territorial waters. As Feldtmann briefly raises in the chapter on the international law, the provisions of the United Nations Convention for the Law of the Sea (UNCLOS) might be interpreted in different ways by different coastal states and the legal uncertainties have been a factor in the development of floating armouries, which again leads to a number of legal questions and uncertainties.

Third, the country reports illustrate clearly that the division of powers between administrative bodies and private actors varies greatly between the different flag states. While the German system is dominated by a tight, state-based authorisation process, the Danish system leaves most of the responsibilities to private actors (ship owners and security providers), and the state authorities have in fact a minor role in the process. This means that there are differences in the level of state control. 
The foregoing means that security companies, while providing the same kind of services, have to operate in and deal with a complex mixture of diverse national approaches and regulations. Thus, having gained authorisation to operate under one system does not mean that the same service provider can provide the same service under another system without any further obstacles. This is interesting as the shipping industry deals in international trade and is very much used to harmonisation and standardisation.

\section{Controlling Violence: The Cross-cutting Issue of the Use of Force}

The international perspective and the four country reports clearly illustrate that one of the crucial topics in connection with both the employment of PCASPs and VPDs is the issue of the use of force. This raises the following question: what is the legal framework regarding the use of weapons to repel pirate attacks and as a last resort to take human lives?

The question of the use of force is essentially a question of 'controlling violence' and also a question of the distribution of powers between states and their citizens. From a legal perspective, the question of the use of force can be reflected upon from different points of departure with different connected legal considerations. One point of departure is the perspective of the international law of the sea, which, as shown by Feldtmann, does not explicitly deal with the use of force, neither in connection with state actors' use of force in a general law enforcement or in a specific counter-piracy setting, nor with a view to private actors exercising the individual right to self-defence. Nevertheless, the use of force exercised in self-defence is implicitly taken for granted in the legal regime established by the law of the sea, without giving any further guidance.

Another point of departure is the human rights perspective. Italy, Denmark, Germany and the Netherlands are all party to the European Convention on Human Rights (ECHR) and the scope of Article 2 of ECHR is central in any approach to the control of violence and threats to life. In a nutshell, the human rights perspective leads to at least two obligations. First, the state's use of lethal force against individuals must be limited to an absolute minimum and can only be used as a last resort. Second, the individual right to life is linked to the individual right to self-defence, meaning that the protection of innocent lives can, as a last resort, justify the taking of 'less innocent' lives. From a state-based perspective, as shown in the Dutch country report and briefly mentioned earlier, the issue of the use of force can on the national level be perceived as a crucial question of the state's monopoly on force. This perspective was also raised in Germany. What might be surprising is that it seems that the question of the state's monopoly on force has not been raised in all countries - in Denmark a similar discussion has basically been absent. One could argue that the question of the state's monopoly on force is not really challenged if the protection of vessels is exclusively seen from a self-protection perspective; the issue at stake is not the transfer of state powers to private actors, but an issue of the individual right to selfdefence and nothing more. This seems to be the conclusion in Germany and the underlying assumption in Denmark.

The issue of the use of force by PCASPs and the specific boundaries for legitimate self-defence are a subject for regulation on the national level. The country reports indicate that a typical approach is to rely on the general principle of self-defence in criminal law and not to develop a specific legal framework for the use of force in this specific setting. German lawmakers have gone one step further by trying to operationalise the concept. Only the Netherlands have opted for the VPD approach and are not leaning on the general concept of selfdefence in criminal law. As shown in the Danish country report, maritime stakeholders might turn to soft-law instruments for guidance on how to operationalise the right to self-defence in case of pirate attacks. In this context, the German approach is interesting: the outline of the German legal system shows that the issue of the use of force/self-defence is included in the process of authorisation. The aim seems here to be to ensure sufficient knowledge of the legal framework for self-defence and thereby ensuring some kind of control over the use of force on the vessel. It might also be worthwhile to mention that Italy and Germany require special licences for the use of particular weapons (especially semiautomatic weapons).

Another important issue in connection with the control of the use of force is reporting obligations (post-incident reports) and other oversight mechanisms. All regulatory models seem to struggle with the difficulty of securing the control of the use of force on a vessel far from all of the usual (land-based) systems of compliance. To bridge the gap, all countries have incorporated systems of reporting; reporting to maritime authorities or the Ministry of Justice, or even to the public prosecutors. Interestingly, there is a dualistic approach of double-reporting (master and team leader) in Germany and the Netherlands, whereas in Denmark only one report (issued by the ship owner and based on information provided by the master) is sufficient.

In the German system, the obligatory use of cameras was discussed but not made mandatory. The upcoming Dutch legislation, which is the result of intense discussions in the Dutch Parliament, requires that armed guards use cameras. Associated camera recordings will have to be annexed to reports about specific incidents in which weapons were used. Reading this provision from a criminal law perspective, one might add that, as we can read in the country reports, the Italian and German regulations provide for specific provisions to protect the persons involved against an obligation of self-incrimination (nemo tenetur principle), whereas the Dutch and the 
Danish laws do not contain any provision in this respect. Under the law of the latter, guards and the master must turn to the general ECHR protection principles in this respect.

\section{Chain of Command: The Cross-cutting Issue of Who Is in Charge}

Another interesting observation in connection with the country reports is that there were quite similar discussions about the exact position of the master, his authority and responsibility if on-board protection is used. Remarkably, this is one of the few topics where the international law of the sea provides for a rather clear legal basis: the overall authority of the master on all matters connected to the vessels, its navigation and crew is articulated in a number of conventions, for example, in the International Convention for the Safety of Life at Sea (SOLAS), Regulation 34.1. However, the question remains what this legal position means in practice if we connect the master's authority with the specific topics of the use of force and the individual right to self-defence. First, those topics do not normally fall under the master's training and experience. Second, as pointed out by Feldtmann, in practice the relation and division of powers between the master, team leader and individual guard is rather complex. This point is illustrated by looking at the provisions in Italy, Germany and the Netherlands. According to the Dutch parliamentary debate, the responsibility and criminal liability of the master is limited to obvious cases in which he must use his authority to stop the obvious use of disproportionate violence as decided and ordered by the team leader (after consultation with the master). But in Germany and Italy, the same overall authority of the master, as codified in the International Law of the Sea, has resulted in a different interpretation. According to Italian law, the master has to order the use of violence, for example, the occupation of the defensive positions on board and the preparation to use firearms. Interestingly, this rather important question has not played a particular role in the Danish discussions. These different interpretations and rules concerning the master's position in connection with the use of force/self-defence lead to a situation where the masters must meet different requirements in different flag states. The question of responsibility of the master in connection with the use of force can have an implication for a possible criminal liability; however, it does not mean that the master is the first or only person to face investigations and prosecution in case of disproportionate use of force.

\section{Concluding Remarks/ Schlussbemerkung/Ten slotte/konklusion/ conclusioni}

In the introduction to this special issue it was predicted that the regulatory models on the national level in Denmark, Germany, Italy and the Netherlands might differ at a level that we have called the 'level of privatisation'. We stated earlier that we would return to this perspective in this final contribution. Given the informative and comprehensive country reports, the differentiation in the level of privatisation is obvious. However, recent developments have lessened these differences regarding the level of privatisation.

Perhaps this observation is more important: it is our conclusion that the differences in the level of privatisation are not necessarily the main points of relevance when it comes to evaluating the national approaches and provisions. More important is the answer to the question of to what extent national law provides for sufficiently detailed regulation and control mechanisms to address the complex and sensitive aspects of on-board protection in general and in the use of PCASPs in particular. How are the employment of PCASPs and their (potential) use of firearms and the related risks guided, regulated and controlled by the flag state at hand? One can argue that even if this leads to diverse approaches for security companies to navigate in, it could be an advantage if national legal systems deal with the issues at hand as long as they do their utmost to regulate and control the use of PCASPs and the subsequent use of force in their national law as specifically and effectively as possible. An alternative could be common European or international uniform rules which possibly would not rise over a basic level of guarantees and control. In reality, the different approaches and regulations under national law of a 'tight' approach with strong regulation and 'quality control' could result in an economic advantage: Salomon describes that the detailed German system of authorisation could function as a 'seal of approval' and 'quality guarantee' for companies that have met these high standards. On the other hand, a complicated and expensive authorisation process or state-based model might lead to threats of reflagging. However, if a flag state wants to brand itself as a 'quality' flag state, a responsible approach should be the preferable one.

Our final conclusion is that the issue of the use of firearms and associated risks calls for regulations that take more than the economic perspective into account. We believe that all four flag states that are described in this special issue understand this very well. However, they have chosen rather different approaches. None of them seem to have found the 'definitive' (optimal) solution to all associated problems and legal uncertainties, and perhaps the suspicion is that there is no solution which fits 
all. There is also another aspect associated with this: at the end of the day, violence, however well-regulated and controlled, will never be the final, sole answer to any complex problem. To be frank: the use of armed onboard protection, be it PCASPs or VPDs, should be considered as management of a symptom rather than a long-term solution. It should be only one of many approaches towards modern piracy, which is a complex phenomenon and a problem the international community must solve by taking a comprehensive approach. As the former U.S. Secretary of State, Hillary Clinton, put it so clearly in connection with the Maersk Alabama incident in 2009 (as cited in our introduction): 'We may be dealing with a 17 th-century crime, but we need to bring 21 st century solutions to bear.' It seems that the international community, as shown by Feldtmann, has understood this and the three-pillar approach of the international community and the maritime stakeholders towards the Somali problem of piracy has been somewhat successful. It is important to keep the momentum going and to continue to deal with the problem of piracy by multiple, supplementary approaches, guided by human rights and the fundamental principles of the rule of law. 